5-1-2014

\title{
Specifying Asymmetric STAR models with Linear and Nonlinear GARCH Innovations: Monte Carlo Approach
}

\author{
OlaOluwa S. Yaya \\ University of Ibadan, Nigeria, os.yaya@mail.ui.edu.ng \\ Olanrewaju I. Shittu \\ University of Ibadan, Nigeria, oi.shittu@ui.edu.ng
}

Follow this and additional works at: http://digitalcommons.wayne.edu/jmasm

Part of the Applied Statistics Commons, Social and Behavioral Sciences Commons, and the Statistical Theory Commons

\section{Recommended Citation}

Yaya, OlaOluwa S. and Shittu, Olanrewaju I. (2014) "Specifying Asymmetric STAR models with Linear and Nonlinear GARCH Innovations: Monte Carlo Approach," Journal of Modern Applied Statistical Methods: Vol. 13 : Iss. 1 , Article 27.

DOI: $10.22237 /$ jmasm/1398918360

Available at: http://digitalcommons.wayne.edu/jmasm/vol13/iss1/27

This Regular Article is brought to you for free and open access by the Open Access Journals at DigitalCommons@WayneState. It has been accepted for inclusion in Journal of Modern Applied Statistical Methods by an authorized editor of DigitalCommons@WayneState. 


\section{Specifying Asymmetric STAR models with Linear and Nonlinear GARCH Innovations: Monte Carlo Approach}

\author{
OlaOluwa S. Yaya \\ University of Ibadan \\ Ibadan, Nigeria
}

\author{
Olanrewaju I. Shittu \\ University of Ibadan \\ Ibadan, Nigeria
}

Economic and finance time series are typically asymmetric and are expected to be modeled using asymmetrical nonlinear time series models. Smooth Transition Autoregressive (STAR) models: Logistic (LSTAR) and Exponential (ESTAR) are known to be asymmetric and symmetric respectively. Under non-normal and heteroscedastic innovations, the residuals of these models are estimated using Generalized Autoregressive Conditionally Heteroscedastic (GARCH) models with variants which include linear and nonlinear forms. The small sample properties of STAR-GARCH variants are yet to be established but these properties are investigated using Monte Carlo (MC) simulation. An MC investigation was conducted to investigate the performance of selections of STAR-GARCH models by classical nonlinear selection approaches. The $\operatorname{ARCH}(1)$ and $\operatorname{GARCH}(1,1)$ models were the linear GARCH specifications while the Logistic Smooth Transition-ARCH (LST-ARCH(1,1)), Logistic Smooth TransitionGARCH (LST-GARCH(1,1)) and Asymmetric Nonlinear Smooth Transition-GARCH (ANST-GARCH(1,1)) models were the nonlinear GARCH specifications. The nonlinearity parameter in the variance equations and Autoregressive (AR) parameters were varied along with different sample sizes. With the assumption of normality, the results showed that the selection of LSTAR models were actually affected by the structure of the innovations and this improved as sample size increased. Misspecification tests showed that these models cannot be misrepresented in the real sense.

Keywords: Asymmetry, Monte Carlo simulations, nonlinear GARCH, Smooth transition autoregression, specification

\section{Introduction}

Smooth Transition Autoregressive (STAR) and Generalized Conditionally Heteroscedastic $(\mathrm{GARCH})$ models are gaining their popularities in economics and

OlaOluwa S. Yaya is a Lecturer in the Department of Statistics. Email at: os.yaya@mail.ui.edu.ng. Dr. Shittu is a Lecturer in the Department of Statistics. Email at oi.shittu@ui.edu.ng. 
finance. STAR models of Granger and Teräsvirta (1993) classify market into two phases of contraction and expansion, whereas GARCH model of Bollerslev (1986) is often used to study the behavior of asset returns or innovations of the 'parent' model. In that case, such a 'parent' model is the mean equation and the (GARCH) model is the variance equation. The innovations of the STAR model are expected follow normal distribution (homoscedasticity) but in case this is not true, the innovations are said to possess heteroscedasticity, which can be of various forms (Pavlidis, Paya and Peel, 2010). The mean and variance equations are then compounded as STAR-GARCH model.

Maximum Likelihood Estimation (MLE) of STAR-GARCH model was examined in Chan and McAleer (2002). The structural and statistical properties of the model were also established in the paper, even though the asymptotic normality and finite sample properties are still examined using Monte Carlo simulation approach. Chan and McAleer (2002) also considered the effects of misspecifying the transition functions (logistic or exponential) in the STAR model and the results obtained showed that greater bias will be induced in the GARCH estimates for the STAR-GARCH model whenever STAR mode is misspecified. Their results further showed that Logistic STAR model can easily be substituted for Exponential STAR model.

In the study of financial returns, negative returns tend to be followed by periods of higher volatility than positive returns of the same magnitude, that is negative and positive shocks exert different values for the leverage of a firm which on the long run realize different volatilities (Black, 1976). This property has therefore led to the development of GARCH variants that are robust to asymmetry. These variants are nonlinear in their structures due to the fact that the conditional variance is no longer specified as a linear function of lagged squared error and lagged variance. These common asymmetric variants are the Exponential GARCH (EGARCH) (Nelson, 1991), Asymmetric Power ARCH (APARCH) (Ding, et al., 1993) and Glosten Jaganathan and Runkle (GJRGARCH) (Glosten, et al., 1993) models, but in this work we investigate GARCH variants which display regime switching dynamics.

This study is motivated by the work of Chan and McAleer (2002). We applied the linear GARCH and Smooth Transition specification of ARCH/GARCH models in a Monte Carlo simulation approach. Nonlinearities were first introduced in the ARCH functional form in Engle and Bollerslev (1986). They proposed in their model the dynamics of conditional variance, $\sigma_{t}^{2}$ as it changes with the squared residuals and the transition between different conditional variance determined by normal cumulative distribution function. A 


\section{SPECIFYING ASYMMETRIC STAR MODELS}

few years later, Higgins and Bera (1992) developed a Nonlinear ARCH (NARCH) model which accommodated different functional forms to predict the conditional variance. Apart from the classical ARCH and GARCH models of Engle (1982) and Bollerslev (1986), Smooth Transition ARCH (STARCH), Smooth Transition GARCH (ST-GARCH) and Asymmetric Nonlinear Smooth Transition GARCH (ANST-GARCH) models of Hagerud (1996; 1997), González-Rivera (1998) and Anderson et al. (1999) respectively are also considered. The ST-ARCH model was applied on the Nordic and Stockholm stock returns and found the model better than the linear GARCH model. González-Rivera (1998) used MC simulation experiment to study the model and applied the models on stock returns and exchange-rate data.

\section{The STAR-GARCH and STAR-STGARCH Models}

This article presents compounded regime switching and volatility models, with the regime switching model as the mean equation and volatility models as the variance equation. For a time series $y_{t}, t=1, \ldots, N$ with $y_{t} \sim N\left(\mu, \sigma^{2}\right)$ in the structural model,

$$
\hat{y}_{t}=f(.)+\varepsilon_{t}
$$

where $f($.$) is the function of y_{t}$ and $\varepsilon_{t}$ is the innovation process, expected to be independently and identically distributed with mean 0 and variance 1 that is homoscedasticity case. In the case where this assumption of normal distribution fails, the innovations are estimated with volatility models.

\section{The Mean Equation: STAR model}

The Smooth Transition Autoregressive (STAR) model is introduced in Granger and Teräsvirta (1993) and the specification, estimation and evaluation of the model are itemized following standard procedures in Teräsvirta (1994). Since then, the model has been applied to study nonlinearity in business cycle (Teräsvirta and Anderson, 1992); Skalin and Teräsvirta 1996; 1998) and real exchange rates (Baum et al., 1998; Liew et al., 2002). The connection between business cycle-regimes and nonlinearity in the UK labour market is studied in Acemoglu and Scotts (1994). Öcal (2000) applied STAR model on the nonlinearities in growth rates of some selected UK macroeconomic time series 
and suggest either two-regime or three-regime model for UK economy. Mourelle, Cuestas and Gil-Alana (2011), Shittu and Yaya (2011) and Yaya (2013) considered STAR model for Nigerian inflation series.

Apart from real life time series data that have been considered for the STAR model, Escribano and Jordá (2001) and Yaya and Shittu (2011) investigated the selection of STAR model by varying some of the parameters and conditions in the models and obtained results that serve as guide for nonlinear time series modelers; then, there is need to study, and if possible develop the structural and small sample properties of the STAR model.

The STAR model of order $p$ is given as,

$$
y_{t}=\phi_{10}+\sum_{i=1}^{p} \phi_{1 i} y_{t-i}+\left(\phi_{20}+\sum_{i=1}^{p} \phi_{2 i} y_{t-i}\right) F\left(y_{t-d} ; \gamma, c\right)+\varepsilon_{t}
$$

where $\phi_{10}, \phi_{20}$ are the constants and $\phi_{1 i}, \phi_{2 i}(i=1, \ldots, p)$ are the autoregressive parameters of order $p$. The transition function, $F\left(y_{t-d} ; \gamma, c\right)$ causes the nonlinear dynamics in the model, and this are of logistic and exponential forms as given as,

$$
F\left(y_{t-d} ; \gamma, c\right)=\frac{1}{1+\exp \left[-\gamma\left(y_{t-d}-c\right)\right]}
$$

and

$$
F\left(y_{t-d} ; \gamma, c\right)=1-\exp \left[-\gamma\left(y_{t-d}-c\right)^{2}\right]
$$

respectively, with $\gamma>0$ in both cases. The logistic type is known to be asymmetric whereas the exponential type is symmetric. Economic and finance series often exhibit forms of asymmetries, and therefore Logistic STAR (LSTAR) model is often applied to model nonlinear dynamics in the series. In the transition functions, the transition variable is $y_{t-d}$ with $d$ assuming values $1,2, \ldots, p$. the value of $d$ is varied in order to improve nonlinearity in the system when it is not known prior to model estimation. The slope, $\gamma$ and intercept, $c$ are parts of the nonlinearity parameters in the transition function. As $\gamma$ assumes values from 1 to say 100 , the nonlinearity becomes sharper, and the dynamics shift from lower linear region to upper linear region at faster rate, after being in the nonlinear state 


\section{SPECIFYING ASYMMETRIC STAR MODELS}

for some period. At $\gamma=1$, depending on the variance of $y_{t}$ and size of $c$, discrimination between the nonlinear and linear series may not be significant. (Yaya and Shittu, 2011). The transition functions in (3) and (4) are bounded between 0 and 1, and this makes the STAR modelling of interesting application. When the transition function is at zero state, the entire system in (2) becomes linear, and at unity state, it is also linear. Most of the time, the transition function is such that $0<F\left(y_{t-d} ; \gamma, c\right)<1$, which is a nonlinear state.

Specification between the asymmetric and symmetric transition function is often carried out using the approach outlined in Teräsvirta (1994). Though there is a newer specification approach proposed in Escribano and Jordá (2001), the approach of Teräsvirta (1994) is not dominated by that of Escribano and Jordá (2001). Further readings on the specification of STAR models are referred to the two articles as well as Luukkonen, Saikkonnen and Teräsvirta (1988).

\section{The Variance Equation: GARCH and ST-GARCH models}

Apart from the issue of nonlinearity of the time series $y_{t}$, the innovations of the estimated model (mean equation) is often heteroscedastic for economic and finance series to be specific. Engle (1982) proposed the Autoregressive Conditionally Heteroscedastic (ARCH) model of order $q$ for UK inflation.

$$
\sigma_{t}^{2}=w+\sum_{i=1}^{q} \alpha_{i} \varepsilon_{t-i}^{2}
$$

where $\sigma_{t}^{2}$ is the conditional variance, $w$ is the constant and $\alpha_{i}(i=1, \ldots, q)$ are the parameters in the ARCH model. The $\varepsilon_{t-i}$ are the residuals from the mean equation which are assumed to be heteroscedastic.

Bollerslev (1986) proposed the generalized version of Engle's model which is named the Generalized Autoregressive Conditionally Heteroscedastic $(\mathrm{GARCH})$ model of order $(p, q)$ given as,

$$
\sigma_{t}^{2}=w+\sum_{i=1}^{q} \alpha_{i} \varepsilon_{t-i}^{2}+\sum_{j=1}^{r} \beta_{j} \sigma_{t-j}^{2}
$$

where $\beta_{j}(j=1, \ldots, r)$ are the parameters in the GARCH term. In the $\operatorname{ARCH}(q)$ and $\operatorname{GARCH}(q, r)$ models in (5) and (6), w>0, $\alpha_{i} \geq 0$ and $\beta_{j} \geq 0$ and the 
existence of covariance-stationarity is $\sum_{i=1}^{q} \alpha_{i}<1$ for $\operatorname{ARCH}(q)$ and $\sum_{i=1}^{q} \alpha_{i}+\sum_{j=1}^{r} \beta_{j}<1$ for $\operatorname{GARCH}(q, r)$ model.

Hagerud (1996; 1997) and González-Rivera (1998) considered introducing regime switching functional forms in the ARCH/GARCH systems. Their propositions are further developed in Lundbergh and Teräsvirta (1999). Hagerud (1996) proposed Smooth Transition-ARCH $(q)(\mathrm{STARCH})$ model,

$$
\sigma_{t}^{2}=w+\sum_{i=1}^{q} \alpha_{i} \varepsilon_{t-i}^{2}\left[1-F\left(\varepsilon_{t-i}\right)\right]+\sum_{i=1}^{q} \delta_{i} \varepsilon_{t-i}^{2} F\left(\varepsilon_{t-i}\right)
$$

where $w$ and $\alpha_{i}$ are as defined in $\mathrm{ARCH}$ model. The additional parameter, $\delta_{i}(i=1, . ., q)$ defines the model in two-regimes. The transition function, with the transition variable $\varepsilon_{t-i}$ is of logistic and exponential as well. These are given as,

$$
F\left(\varepsilon_{t-i}\right)=\frac{1}{1+\exp \left(-\theta \varepsilon_{t-i}\right)}
$$

and

$$
F\left(\varepsilon_{t-i}\right)=1-\exp \left(-\theta \varepsilon_{t-i}^{2}\right)
$$

for the two forms respectively with $\theta>0$ in both cases. The two transition functions in (8) and (9) will generate different data dynamics for the conditional variance. The logistic form in (8) will produce a return process where the dynamics of the conditional variance differ depending on the signs of the innovations (Hagerud, 1997). As $\varepsilon_{t-j} \rightarrow-\infty$, the logistic function equals to $-1 / 2$ and as $\varepsilon_{t-j} \rightarrow+\infty$, the function equals to $-1 / 2$. The exponential function in (9) is symmetric with respect to the sign of the error term, hence it generates data for which the dynamics of the conditional variance depends only on the magnitude of the innovations. As $\left|\varepsilon_{t-j}\right| \rightarrow \infty$, the impact of $\varepsilon_{t-1}^{2}$ on $\sigma_{t}^{2}$ changes smoothly from $\alpha_{i}$ to $\delta_{i}$ in both logistic $\operatorname{ST}-\operatorname{ARCH}(q)$ and $\operatorname{ST}-\operatorname{GARCH}(q, r)$ when the function equals 1 , and as $\varepsilon_{t-j}=0$, the logistic function equals 0 . Also, as the parameter $\theta$ 


\section{SPECIFYING ASYMMETRIC STAR MODELS}

becomes larger, both the logistic ST-ARCH and ST-GARCH functions approach step functions which equal 0 for negative $\varepsilon_{t-1}$ and 1 for positive $\varepsilon_{t-1}$, therefore, for logistic function, $-1 / 2 \leq F(.) \leq 1 / 2$ and for exponential function, $0 \leq F() \leq$.1 .

For positive conditional variance in the logistic ST-ARCH model, the condition $\alpha_{i} \geq \frac{1}{2}\left|\delta_{i}\right|$ and for stationarity of the innovations $\varepsilon_{t}$, $\sum_{i=1}^{q}\left[\alpha_{i}-\frac{1}{2}\left|\delta_{i}\right|+\max \left(\delta_{i}, 0\right)\right]<1$. For the positive conditional mean in the exponential ST-ARCH, $\alpha_{i}+\delta_{i} \geq 0$ and for stationarity of the innovations $\varepsilon_{t}$, $\sum_{i=1}^{q}\left[\alpha_{i}+\max \left(\delta_{i}, 0\right)\right]<1$ (Hagerud, 1997).

The generalized form of the model called Smooth Transition-GARCH $(q, r)$ (ST-GARCH) is proposed in Hagerud (1997) and González-Rivera (1998) as,

$$
\sigma_{t}^{2}=w+\sum_{i=1}^{q} \alpha_{i} \varepsilon_{t-i}^{2}\left[1-F\left(\varepsilon_{t-i}\right)\right]+\sum_{i=1}^{q} \delta_{i} \varepsilon_{t-i}^{2} F\left(\varepsilon_{t-i}\right)+\sum_{j=1}^{r} \beta_{j} \sigma_{t-j}^{2}
$$

with the transition functions in (8) and (9) for the logistic and exponential cases respectively. The ST-GARCH model only included the GARCH term, $\sigma_{t-j}^{2}$.

For positive conditional variance in the logistic ST-GARCH model, all the covariance stationarity condition of $\operatorname{GARCH}(p, q)$ model hold here in STGARCH, and apart from these, $\alpha_{i} \geq \frac{1}{2}\left|\delta_{i}\right|$ for the logistic case and for the stationarity of the innovations $\varepsilon_{t}, \sum_{i=1}^{q}\left[\alpha_{i}-\frac{1}{2}\left|\delta_{i}\right|+\max \left(\delta_{i}, 0\right)\right]+\sum_{i=1}^{r} \beta_{j}<1$. For the positive conditional mean in the exponential ST-GARCH, $\alpha_{i}+\delta_{i} \geq 0$ and for stationarity of the innovations $\varepsilon_{t}, \sum_{i=1}^{q}\left[\alpha_{i}+\max \left(\delta_{i}, 0\right)\right]<1$ (Hagerud, 1997).

A similar ST-GARCH $(p, q)$ is proposed in Anderson, et al. (1999) and applied recently in Nam, et al. (2002). This is given as, 


$$
\begin{aligned}
\sigma_{t}^{2} & =\left(w_{10}+\sum_{i=1}^{q} \alpha_{1 i} \varepsilon_{t-i}^{2}+\sum_{j=1}^{r} \beta_{1 j} \sigma_{t-j}^{2}\right)\left[1-F\left(\varepsilon_{t-i}\right)\right] \\
& +\left(w_{20}+\sum_{i=1}^{q} \alpha_{2 i} \varepsilon_{t-i}^{2}+\sum_{j=1}^{r} \beta_{2 j} \sigma_{t-j}^{2}\right) F\left(\varepsilon_{t-i}\right)
\end{aligned}
$$

This is a variant of GARCH model in regime switching functional form. The parameters and the conditions of existence of GARCH as defined for the GARCH specification in (6) holds for the ST-GARCH model. The model in (11) is defined only for the asymmetric function (8), and therefore, the ST-GARCH model is otherwise known as Asymmetric nonlinear Smooth Transition-GARCH (ANSTGARCH) model (Nam, et al., 2002). Franses and van Dijk (2003) showed that there is similarity between the ST-GARCH $(q, r)$ model of Hagerud (1997), even in the conditions of existence of conditional volatility and stationarity. Our selection of asymmetric variants of GARCH in this paper is based on similarity with STAR model and their abilities to realize smooth changing dynamics.

\section{Structure of the Data Generating Process and Nonlinearity Tests}

The structure of the Data Generating Process (DGP) model used in the simulation is first explained analytically using a particular STAR model used in Granger and Teräsvirta (1993), Teräsvirta, Lin and Granger (1993), Teräsvirta (1994), Escribano, Franses and van Dijk (1998), Escribano and Jordá (2001) and Lopes and Salazar (2006). The DGP is examined by varying the nonlinearity parameters in the models. From the results, nonlinearity tests are described. The DGP is,

$$
y_{t}=1.8 y_{t-1}-1.06 y_{t-2}+\left(\phi_{20}-0.9 y_{t-1}+0.795 y_{t-2}\right) F\left(y_{t-d} ; \gamma, c\right)+\varepsilon_{t}
$$

where $\varepsilon_{t} \sim N\left(0,0.1 \sigma_{t}\right)$ and $F\left(y_{t-d} ; \gamma, c\right)$ is either the logistic or exponential transition function as given in (3) and (4) respectively. The $\phi_{20}$ is the intercept in the nonlinear part of the Autoregressive model.

Following Teräsvirta (1994), the LSTAR transition function in (3) is approximated by the third order Taylor's series expansion as, 


\section{SPECIFYING ASYMMETRIC STAR MODELS}

$$
\begin{aligned}
F\left(y_{t-d} ; \gamma, c\right) \approx & -\left(\frac{1}{4} c \gamma+\frac{1}{48} \gamma^{3} c^{3}\right)+\left(\frac{1}{4} \gamma+\frac{c^{2} \gamma^{3}}{16}\right) y_{t-d} \\
& -\frac{1}{16} c \gamma^{3} y_{t-d}^{2}+\frac{1}{48} \gamma^{3} y_{t-d}^{3}+R .
\end{aligned}
$$

where $R$ is the remainder series.

Substituting $\gamma=100$ and $c=0.2$, then (13) becomes

$$
F\left(y_{t-d} ; \gamma, c\right) \approx-20838.33+2525 y_{t-d}-12500 y_{t-d}^{2}+20833.33 y_{t-d}^{3}
$$

this is then substituted in (12) to obtain

$$
\begin{aligned}
y_{t} & =\left(-20838.3 \phi_{20}+18751.8 y_{t-1}-16567.5 y_{t-2}\right) \\
& +\left(2525 \phi_{20}-2272.5 y_{t-1}+2007.4 y_{t-2}\right) y_{t-d} \\
& +\left(-12500 \phi_{20}-11250 y_{t-1}+9937.5 y_{t-2}\right) y_{t-d}^{2} \\
& +\left(20833.3 \phi_{20}-18750 y_{t-1}+16562.5 y_{t-2}\right) y_{t-d}^{3}+R^{*}
\end{aligned}
$$

The expansion in (15) can be generalized as,

$$
y_{t}=\phi^{\prime} y_{t}^{(2)}+\beta_{1}^{\prime} y_{t}^{(2)} y_{t-d}+\beta_{2}^{\prime} y_{t}^{(2)} y_{t-d}^{2}+\beta_{3}^{\prime} y_{t}^{(2)} y_{t-d}^{3}+\vartheta_{t}
$$

where $\vartheta_{t}$ is some noise process and $y_{t}^{(2)}$ is the AR process of order 2 and $\beta_{1}, \beta_{2}$ and $\beta_{3}$ are the parameters of the nonlinear regression model. From (16), the LSTAR model is specified if the parameter $\beta_{2}$ is not significant at $\alpha$-level or if it is the least significant among the three betas. Otherwise, ESTAR is specified.

Similar nonlinearity test to the above is developed in Escribano and Jordá (2001). Here there is suggestion to apply second order Taylor's series expansion of the ESTAR function in (4) to approximate the transition function. The approximation is given as,

$$
\begin{aligned}
& F\left(y_{t-d} ; \gamma, c\right) \approx\left(\gamma c^{2}-\frac{1}{2} \gamma^{2} c^{4}\right)+\left(2 c^{3} \gamma^{2}-2 c \gamma\right) y_{t-d} \\
&+\left(\gamma-3 c^{2} \gamma^{2}\right) y_{t-d}^{2}+2 c \gamma^{2} y_{t-d}^{3}-\frac{1}{2} \gamma^{2} y_{t-d}^{4}+R .
\end{aligned}
$$


Substituting $\gamma=100$ and $c=0.2$, then (17) becomes

$$
F\left(y_{t-d} ; \gamma, c\right) \approx-12+120 y_{t-d}-1100 y_{t-d}^{2}+4000 y_{t-d}^{3}+5000 y_{t-d}^{4}
$$

this is then substituted in (12) to obtain

$$
\begin{aligned}
y_{t} & =\left(-12 \phi_{20}+12.4 y_{t-1}-11.6 y_{t-2}\right) \\
& +\left(120 \phi_{20}-108 y_{t-1}+95.4 y_{t-2}\right) y_{t-d} \\
& +\left(-1100 \phi_{20}-990 y_{t-1}+874.5 y_{t-2}\right) y_{t-d}^{2} \\
& +\left(4000 \phi_{20}-3600 y_{t-1}+3180 y_{t-2}\right) y_{t-d}^{3} \\
& +\left(5000 \phi_{20}-4500 y_{t-1}+3975 y_{t-2}\right) y_{t-d}^{4}+R^{*}
\end{aligned}
$$

The expansion in (19) can be generalized as,

$$
y_{t}=\phi^{\prime} y_{t}^{(2)}+\beta_{1}^{\prime} y_{t}^{(2)} y_{t-d}+\beta_{2}^{\prime} y_{t}^{(2)} y_{t-d}^{2}+\beta_{3}^{\prime} y_{t}^{(2)} y_{t-d}^{3}+\beta_{4}^{\prime} y_{t}^{(2)} y_{t-d}^{4}+\vartheta_{t}
$$

Here, the parameters are of order 2 and LSTAR is specified once the odd parameters $\beta_{1}$ and $\beta_{3}$ are most significant. Otherwise, ESTAR is specified if the parameters $\beta_{2}$ and $\beta_{4}$ are most significant.

\section{Monte Carlo Simulation Experiment}

The Data Generating Process (DGP) defined as,

$$
y_{t}=1.8 y_{t-1}-1.06 y_{t-2}+\left(\phi_{20}-0.9 y_{t-1}+0.795 y_{t-2}\right) F\left(y_{t-d} ; \gamma, c\right)+\varepsilon_{t}
$$

with the nonlinear transition functions $F\left(y_{t-d} ; \gamma, c\right)=\frac{1}{1+\exp \left[-100\left(y_{t-1}-0.2\right)\right]}$ and $F\left(y_{t-d} ; \gamma, c\right)=1-\exp \left[-100\left(y_{t-1}-0.2\right)^{2}\right]$ for Logistic STAR and Exponential STAR respectively. In the DGP, the autoregressive parameter $\phi_{20}$ is varied as $\phi_{20}=\{0,0.2,0.5\}$ and the innovations are assumed to have non-constant variance, that is $\varepsilon_{t} \sim N\left(0,0.1 \sigma_{t}\right)$. The values of $\phi_{20}$ are chosen such that the DGP will 


\section{SPECIFYING ASYMMETRIC STAR MODELS}

realized stationary series. At $F\left(s_{t} ; \gamma, c\right)=0$, the resulting linear model has complex roots that are less than unity in absolute term, hence the process becomes nonstationary and there is possibility of explosion. At $F\left(s_{t} ; \gamma, c\right)=1$, the behavior of the process is influenced by the values of $\phi_{20}$. For example, when $\phi_{20}=\{0,0.2\}$, the resulting characteristic equation has complex roots that are less than unity in absolute terms, hence the system reverts back to stationary region. At $\phi_{20}=0.5$, the roots of the characteristic equations are real and the system realize nonstationary series.

The variance equations used in the simulations are the ARCH (1), GARCH $(1,1)$, STARCH (1), ST-GARCH $(1,1)$ and ANST-GARCH $(1,1)$ are:

$$
\begin{aligned}
\sigma_{t}^{2} & =0.02+0.3 \varepsilon_{t-1}^{2} \\
\sigma_{t}^{2} & =0.02+0.3 \varepsilon_{t-1}^{2}+0.6 \sigma_{t-1}^{2} \\
\sigma_{t}^{2} & =0.02+0.3 \varepsilon_{t-1}^{2}\left[1-F\left(\varepsilon_{t-1}\right)\right]+0.5 \varepsilon_{t-1}^{2} \\
\sigma_{t}^{2} & =0.02+0.3 \varepsilon_{t-1}^{2}\left[1-F\left(\varepsilon_{t-1}\right)\right]+0.5 F\left(\varepsilon_{t-1}\right)+0.6 \sigma_{t-1}^{2} \\
\sigma_{t}^{2} & =0.05+0.5 \varepsilon_{t-1}^{2}+0.3 \sigma_{t-1}^{2}\left[1-F\left(\varepsilon_{t-1}\right)\right] \\
& +\left(0.02+0.3 \varepsilon_{t-1}^{2}+0.6 \sigma_{t-1}^{2}\right) F\left(\varepsilon_{t-1}\right)
\end{aligned}
$$

The logistic and exponential functions for the innovations $\varepsilon_{t}$ are $F\left(\varepsilon_{t-1}\right)=\frac{1}{1+\exp \left(-\theta \varepsilon_{t-1}\right)}$ and $F\left(\varepsilon_{t-1}\right)=1-\exp \left(-\theta \varepsilon_{t-1}^{2}\right)$ respectively. In each case, the nonlinear parameter in the variance equations in (14) to (18) is varied as $\theta=\{1,5,10\}$. The experiment is carried out over 1,000 replications with sample sizes $N=\{50,100,200,500,1000\}$. Initialization problem is catered for by discarding the first 100 observations in each replication.

The experiment was carried out in two scenarios: 


\section{YAYA \& SHITTU}

1. When the LSTAR DGP was used to realize LSTAR series with the specifications of the variance equations (Tables 1-3). When ESTAR model was misspecified for LSTAR model (Tables 4-6).

2. The relative frequencies of selecting an asymmetric STAR model with a particular variance equation are computed on every 1,000 replications at 5\% nominal significant level.

The relative frequencies of selecting an asymmetric STAR model with a particular variance equation are computed on every 1,000 replications at $5 \%$ nominal significant level. 


\section{SPECIFYING ASYMMETRIC STAR MODELS}

\section{When the LSTAR DGP is used to realise LSTAR series.}

Table 1. Selection Frequencies of models at different $\phi_{20}$ with fixed $\theta=1$

\begin{tabular}{|c|c|c|c|c|c|c|c|c|c|c|}
\hline \multicolumn{11}{|c|}{$\phi_{20}=0, \theta=1$} \\
\hline \multirow[t]{2}{*}{$N$} & \multicolumn{2}{|c|}{$\begin{array}{l}\text { LSTAR- } \\
\text { ARCH }\end{array}$} & \multicolumn{2}{|c|}{$\begin{array}{l}\text { LSTAR- } \\
\text { GARCH }\end{array}$} & \multicolumn{2}{|c|}{$\begin{array}{c}\text { LSTAR- } \\
\text { LSTARCH }\end{array}$} & \multicolumn{2}{|c|}{$\begin{array}{c}\text { LSTAR- } \\
\text { LSTGARCH }\end{array}$} & \multicolumn{2}{|c|}{$\begin{array}{c}\text { LSTAR- } \\
\text { ANLSTGARCH }\end{array}$} \\
\hline & $T P$ & EJP & $T P$ & EJP & $T P$ & $E J P$ & $T P$ & $E J P$ & $T P$ & $E J P$ \\
\hline 50 & 0.522 & 0.934 & 0.692 & 0.879 & 0.551 & 0.918 & 0.683 & 0.875 & 0.697 & 0.875 \\
\hline 100 & 0.627 & 0.988 & 0.772 & 0.961 & 0.643 & 0.980 & 0.777 & 0.963 & 0.803 & 0.956 \\
\hline 200 & 0.707 & 0.999 & 0.903 & 0.996 & 0.741 & 0.998 & 0.902 & 0.996 & 0.917 & 0.994 \\
\hline 500 & 0.869 & 1.000 & 0.990 & 1.000 & 0.872 & 1.000 & 0.992 & 1.000 & 0.994 & 1.000 \\
\hline 1000 & 0.949 & 1.000 & 1.000 & 1.000 & 0.966 & 1.000 & 1.000 & 1.000 & 1.000 & 1.000 \\
\hline
\end{tabular}

\begin{tabular}{|c|c|c|c|c|c|c|c|c|c|c|}
\hline \multicolumn{11}{|c|}{$\phi_{20}=0.2, \theta=1$} \\
\hline \multirow[t]{2}{*}{$N$} & \multicolumn{2}{|c|}{$\begin{array}{c}\text { LSTAR- } \\
\text { ARCH }\end{array}$} & \multicolumn{2}{|c|}{$\begin{array}{l}\text { LSTAR- } \\
\text { GARCH }\end{array}$} & \multicolumn{2}{|c|}{$\begin{array}{l}\text { LSTAR- } \\
\text { LSTARCH }\end{array}$} & \multicolumn{2}{|c|}{$\begin{array}{c}\text { LSTAR- } \\
\text { LSTGARCH }\end{array}$} & \multicolumn{2}{|c|}{$\begin{array}{c}\text { LSTAR- } \\
\text { ANLSTGARCH }\end{array}$} \\
\hline & $T P$ & $E J P$ & $T P$ & $E J P$ & TP & $E J P$ & $T P$ & $E J P$ & $T P$ & $E J P$ \\
\hline 50 & - & - & - & - & - & - & - & - & - & - \\
\hline 100 & - & - & - & - & - & - & - & - & - & - \\
\hline 200 & - & - & - & - & - & - & - & - & - & - \\
\hline 500 & - & - & 0.598 & 0.500 & - & - & 0.623 & 0.500 & 0.590 & 0.494 \\
\hline 1000 & - & - & 0.672 & 0.554 & - & - & 0.630 & 0.507 & 0.670 & 0.557 \\
\hline
\end{tabular}

\begin{tabular}{|c|c|c|c|c|c|c|c|c|c|c|}
\hline \multicolumn{11}{|c|}{$\phi_{20}=0.5, \theta=1$} \\
\hline \multirow[t]{2}{*}{$N$} & \multicolumn{2}{|c|}{$\begin{array}{l}\text { LSTAR- } \\
\text { ARCH }\end{array}$} & \multicolumn{2}{|c|}{$\begin{array}{l}\text { LSTAR- } \\
\text { GARCH }\end{array}$} & \multicolumn{2}{|c|}{$\begin{array}{l}\text { LSTAR- } \\
\text { LSTARCH }\end{array}$} & \multicolumn{2}{|c|}{$\begin{array}{c}\text { LSTAR- } \\
\text { LSTGARCH }\end{array}$} & \multicolumn{2}{|c|}{$\begin{array}{c}\text { LSTAR- } \\
\text { ANLSTGARCH }\end{array}$} \\
\hline & $T P$ & $E J P$ & $T P$ & $E J P$ & $T P$ & EJP & $T P$ & EJP & $T P$ & $E J P$ \\
\hline 50 & - & - & - & - & - & - & - & - & - & - \\
\hline 100 & - & - & - & - & - & - & - & - & - & - \\
\hline 200 & - & - & - & - & - & - & - & - & - & - \\
\hline 500 & - & - & - & - & - & - & - & - & - & - \\
\hline 1000 & - & - & - & - & - & - & - & - & - & - \\
\hline
\end{tabular}

Note: Table 1 presents the results of the selections of LSTAR models with forms of heteroscedastic innovation processes. EJP performed better than TP in selecting the LSTAR models at zero intercept, $\phi_{20}=0$ of the DGP. Both LSTAR-GARCH and LSTAR-ANLSTGARCH models were detected at frequencies higher than that of other model variants. As $\phi_{20}$ increased beyond 0 , there was failure in model specifications as a result of matrix inversion problems encountered by the simulator. The results were worse when computed at the nonstationary region $\left(\phi_{20}=\{0.2,0.5\}\right)$ of the DGP. 


\section{YAYA \& SHITTU}

Table 2. Selection Frequencies of models at different $\phi_{20}$ with fixed $\theta=5$

\begin{tabular}{|c|c|c|c|c|c|c|c|c|c|c|}
\hline \multicolumn{11}{|c|}{$\phi_{20}=0, \theta=5$} \\
\hline \multirow[t]{2}{*}{$N$} & \multicolumn{2}{|c|}{$\begin{array}{c}\text { LSTAR- } \\
A R C H\end{array}$} & \multicolumn{2}{|c|}{$\begin{array}{l}\text { LSTAR- } \\
\text { GARCH }\end{array}$} & \multicolumn{2}{|c|}{$\begin{array}{c}\text { LSTAR- } \\
\text { LSTARCH }\end{array}$} & \multicolumn{2}{|c|}{$\begin{array}{c}\text { LSTAR- } \\
\text { LSTGARCH }\end{array}$} & \multicolumn{2}{|c|}{$\begin{array}{c}\text { LSTAR- } \\
\text { ANLSTGARCH }\end{array}$} \\
\hline & $T P$ & $E J P$ & $T P$ & $E J P$ & $T P$ & $E J P$ & $T P$ & EJP & $T P$ & EJP \\
\hline 50 & 0.522 & 0.934 & 0.692 & 0.879 & 0.549 & 0.921 & 0.682 & 0.868 & 0.697 & 0.878 \\
\hline 100 & 0.627 & 0.988 & 0.772 & 0.961 & 0.647 & 0.979 & 0.789 & 0.963 & 0.811 & 0.954 \\
\hline 200 & 0.707 & 0.999 & 0.903 & 0.996 & 0.751 & 0.997 & 0.907 & 0.997 & 0.918 & 0.995 \\
\hline 500 & 0.869 & 1.000 & 0.990 & 1.000 & 0.878 & 1.000 & 0.993 & 1.000 & 0.992 & 1.000 \\
\hline 1000 & 0.949 & 1.000 & 1.000 & 1.000 & 0.962 & 1.000 & 1.000 & 1.000 & 1.000 & 1.000 \\
\hline \multicolumn{11}{|c|}{$\phi_{20}=0.2, \theta=5$} \\
\hline \multirow[t]{2}{*}{$N$} & \multicolumn{2}{|c|}{$\begin{array}{c}\text { LSTAR- } \\
A R C H\end{array}$} & \multicolumn{2}{|c|}{$\begin{array}{l}\text { LSTAR- } \\
\text { GARCH }\end{array}$} & \multicolumn{2}{|c|}{$\begin{array}{c}\text { LSTAR- } \\
\text { LSTARCH }\end{array}$} & \multicolumn{2}{|c|}{$\begin{array}{c}\text { LSTAR- } \\
\text { LSTGARCH }\end{array}$} & \multicolumn{2}{|c|}{$\begin{array}{c}\text { LSTAR- } \\
\text { ANLSTGARCH }\end{array}$} \\
\hline & $T P$ & $E J P$ & $T P$ & $E J P$ & $T P$ & $E J P$ & $T P$ & $E J P$ & $T P$ & $E J P$ \\
\hline 50 & - & - & - & - & - & - & - & - & - & - \\
\hline 100 & - & - & - & - & - & - & - & - & - & - \\
\hline 200 & - & - & - & - & - & - & - & - & - & - \\
\hline 500 & - & - & 0.598 & 0.500 & - & - & 0.620 & 0.496 & 0.605 & 0.488 \\
\hline 1000 & - & - & 0.672 & 0.554 & - & - & 0.631 & 0.483 & 0.687 & 0.556 \\
\hline
\end{tabular}

\begin{tabular}{|c|c|c|c|c|c|c|c|c|c|c|}
\hline \multicolumn{11}{|c|}{$\phi_{20}=0.5, \theta=5$} \\
\hline \multirow[t]{2}{*}{$N$} & \multicolumn{2}{|c|}{$\begin{array}{c}\text { LSTAR- } \\
\text { ARCH }\end{array}$} & \multicolumn{2}{|c|}{$\begin{array}{l}\text { LSTAR- } \\
\text { GARCH }\end{array}$} & \multicolumn{2}{|c|}{$\begin{array}{c}\text { LSTAR- } \\
\text { LSTARCH }\end{array}$} & \multicolumn{2}{|c|}{$\begin{array}{c}\text { LSTAR- } \\
\text { LSTGARCH }\end{array}$} & \multicolumn{2}{|c|}{$\begin{array}{c}\text { LSTAR- } \\
\text { ANLSTGARCH }\end{array}$} \\
\hline & $T P$ & $E J P$ & $T P$ & $E J P$ & $T P$ & $E J P$ & $T P$ & $E J P$ & $T P$ & $E J P$ \\
\hline 50 & - & - & - & - & - & - & - & - & - & - \\
\hline 100 & - & - & - & - & - & - & - & - & - & - \\
\hline 200 & - & - & - & - & - & - & - & - & - & - \\
\hline 500 & - & - & - & - & - & - & - & - & - & - \\
\hline 1000 & - & - & - & - & - & - & - & - & - & - \\
\hline
\end{tabular}

Note: Increasing $\theta$ as 2 in Table 2, similar results to that of Table 2 were obtained. This implies that little increase in the nonlinearity of the residuals may not have significant effect on the specification of STAR models with Smooth Transition GARCH. The results were also worse at $\theta=5$ 


\section{SPECIFYING ASYMMETRIC STAR MODELS}

Table 3. Selection Frequencies of models at different $\phi_{20}$ with fixed 10

\begin{tabular}{|c|c|c|c|c|c|c|c|c|c|c|}
\hline \multicolumn{11}{|c|}{$\phi_{20}=0, \theta=10$} \\
\hline \multirow[t]{2}{*}{$N$} & \multicolumn{2}{|c|}{$\begin{array}{c}\text { LSTAR- } \\
A R C H\end{array}$} & \multicolumn{2}{|c|}{$\begin{array}{l}\text { LSTAR- } \\
\text { GARCH }\end{array}$} & \multicolumn{2}{|c|}{$\begin{array}{c}\text { LSTAR- } \\
\text { LSTARCH }\end{array}$} & \multicolumn{2}{|c|}{$\begin{array}{c}\text { LSTAR- } \\
\text { LSTGARCH }\end{array}$} & \multicolumn{2}{|c|}{$\begin{array}{c}\text { LSTAR- } \\
\text { ANLSTGARCH }\end{array}$} \\
\hline & $T P$ & $E J P$ & $T P$ & $E J P$ & $T P$ & $E J P$ & $T P$ & $E J P$ & $T P$ & $E J P$ \\
\hline 50 & 0.522 & 0.934 & 0.692 & 0.879 & 0.551 & 0.917 & 0.694 & 0.871 & 0.712 & 0.881 \\
\hline 100 & 0.627 & 0.988 & 0.772 & 0.961 & 0.641 & 0.780 & 0.790 & 0.962 & 0.823 & 0.958 \\
\hline 200 & 0.707 & 0.999 & 0.903 & 0.996 & 0.753 & 0.998 & 0.912 & 0.996 & 0.923 & 0.999 \\
\hline 500 & 0.869 & 1.000 & 0.990 & 1.000 & 0.888 & 1.000 & 0.991 & 1.000 & 0.988 & 1.000 \\
\hline 1000 & 0.949 & 1.000 & 1.000 & 1.000 & 0.961 & 1.000 & 0.999 & 1.000 & 1.000 & 1.000 \\
\hline
\end{tabular}

\begin{tabular}{|c|c|c|c|c|c|c|c|c|c|c|}
\hline \multicolumn{11}{|c|}{$\phi_{20}=0.2, \theta=10$} \\
\hline \multirow[t]{2}{*}{$N$} & \multicolumn{2}{|c|}{$\begin{array}{c}\text { LSTAR- } \\
A R C H\end{array}$} & \multicolumn{2}{|c|}{$\begin{array}{l}\text { LSTAR- } \\
\text { GARCH }\end{array}$} & \multicolumn{2}{|c|}{$\begin{array}{l}\text { LSTAR- } \\
\text { LSTARCH }\end{array}$} & \multicolumn{2}{|c|}{$\begin{array}{c}\text { LSTAR- } \\
\text { LSTGARCH }\end{array}$} & \multicolumn{2}{|c|}{$\begin{array}{c}\text { LSTAR- } \\
\text { ANLSTGARCH }\end{array}$} \\
\hline & $T P$ & $E J P$ & $T P$ & EJP & $T P$ & $E J P$ & $T P$ & $E J P$ & $T P$ & $E J P$ \\
\hline 50 & - & - & - & - & - & - & - & - & - & - \\
\hline 100 & - & - & - & - & - & - & - & - & - & - \\
\hline 200 & - & - & - & - & - & - & - & - & - & - \\
\hline 500 & - & - & 0.598 & 0.500 & - & - & 0.616 & 0.496 & 0.605 & 0.477 \\
\hline 1000 & - & - & 0.672 & 0.554 & - & - & 0.644 & 0.450 & 0.690 & 0.530 \\
\hline
\end{tabular}

\begin{tabular}{|c|c|c|c|c|c|c|c|c|c|c|}
\hline \multicolumn{11}{|c|}{$\phi_{20}=0.5, \theta=10$} \\
\hline \multirow[t]{2}{*}{$N$} & \multicolumn{2}{|c|}{$\begin{array}{c}\text { LSTAR- } \\
\text { ARCH }\end{array}$} & \multicolumn{2}{|c|}{$\begin{array}{l}\text { LSTAR- } \\
\text { GARCH }\end{array}$} & \multicolumn{2}{|c|}{$\begin{array}{c}\text { LSTAR- } \\
\text { LSTARCH }\end{array}$} & \multicolumn{2}{|c|}{$\begin{array}{c}\text { LSTAR- } \\
\text { LSTGARCH }\end{array}$} & \multicolumn{2}{|c|}{$\begin{array}{c}\text { LSTAR- } \\
\text { ANLSTGARCH }\end{array}$} \\
\hline & $T P$ & $E J P$ & $T P$ & $E J P$ & $T P$ & $E J P$ & $T P$ & $E J P$ & $T P$ & $E J P$ \\
\hline 50 & - & - & - & - & - & - & - & - & - & - \\
\hline 100 & - & - & - & - & - & - & - & - & - & - \\
\hline 200 & - & - & - & - & - & - & - & - & - & - \\
\hline 500 & - & - & - & - & - & - & - & - & - & - \\
\hline 1000 & - & - & - & - & - & - & - & - & - & - \\
\hline
\end{tabular}

Note: Table 3 gives similar results to Tables 1 and 2. As we see in the previous results that correct model specifications were carried out at intercept $\phi_{20}=0$ and at this point, the process realized stationary time series. 


\section{YAYA \& SHITTU}

\section{When ESTAR model is misspecified for LSTAR model}

Table 4. Selection Frequencies of models at different $\phi_{20}$ with fixed $\theta=1$

\begin{tabular}{|c|c|c|c|c|c|c|c|c|c|c|}
\hline \multicolumn{11}{|c|}{$\phi_{20}=0, \theta=1$} \\
\hline \multirow[t]{2}{*}{$N$} & \multicolumn{2}{|c|}{$\begin{array}{c}\text { LSTAR- } \\
\text { ARCH }\end{array}$} & \multicolumn{2}{|c|}{$\begin{array}{l}\text { LSTAR- } \\
\text { GARCH }\end{array}$} & \multicolumn{2}{|c|}{$\begin{array}{c}\text { LSTAR- } \\
\text { LSTARCH }\end{array}$} & \multicolumn{2}{|c|}{$\begin{array}{c}\text { LSTAR- } \\
\text { LSTGARCH }\end{array}$} & \multicolumn{2}{|c|}{ LSTAR-ANLSTGARCH } \\
\hline & $T P$ & $E J P$ & $T P$ & $E J P$ & $T P$ & EJP & $T P$ & EJP & $T P$ & $E J P$ \\
\hline 50 & - & - & - & - & - & - & - & - & - & - \\
\hline 100 & - & - & - & - & - & - & - & - & - & - \\
\hline 200 & - & - & - & - & - & - & - & - & - & - \\
\hline 500 & - & - & 0.750 & 0.569 & - & - & 0.752 & 0.570 & 0.767 & 0.607 \\
\hline 1000 & - & - & 0.784 & 0.638 & - & - & 0.785 & 0.630 & 0.790 & 0.631 \\
\hline
\end{tabular}

\begin{tabular}{|c|c|c|c|c|c|c|c|c|c|c|}
\hline \multicolumn{11}{|c|}{$\phi_{20}=0.2, \theta=1$} \\
\hline \multirow[t]{2}{*}{$N$} & \multicolumn{2}{|c|}{$\begin{array}{c}\text { LSTAR- } \\
A R C H\end{array}$} & \multicolumn{2}{|c|}{$\begin{array}{l}\text { LSTAR- } \\
\text { GARCH }\end{array}$} & \multicolumn{2}{|c|}{$\begin{array}{l}\text { LSTAR- } \\
\text { LSTARCH }\end{array}$} & \multicolumn{2}{|c|}{$\begin{array}{c}\text { LSTAR- } \\
\text { LSTGARCH }\end{array}$} & \multicolumn{2}{|c|}{ LSTAR-ANLSTGARCH } \\
\hline & $T P$ & $E J P$ & $T P$ & $E J P$ & $T P$ & $E J P$ & $T P$ & EJP & $T P$ & EJP \\
\hline 50 & - & - & - & - & - & - & - & - & - & - \\
\hline 100 & - & - & - & - & - & - & - & - & - & - \\
\hline 200 & - & - & - & - & - & - & - & - & - & - \\
\hline 500 & - & - & 0.614 & 0.470 & - & - & 0.614 & 0.470 & 0.656 & 0.522 \\
\hline 1000 & - & - & 0.673 & 0.554 & - & - & 0.667 & 0.543 & 0.718 & 0.563 \\
\hline
\end{tabular}

\begin{tabular}{|c|c|c|c|c|c|c|c|c|c|c|}
\hline \multicolumn{11}{|c|}{$\phi_{20}=0.5, \theta=1$} \\
\hline \multirow[t]{2}{*}{$N$} & \multicolumn{2}{|c|}{$\begin{array}{c}\text { LSTAR- } \\
\text { ARCH }\end{array}$} & \multicolumn{2}{|c|}{$\begin{array}{l}\text { LSTAR- } \\
\text { GARCH }\end{array}$} & \multicolumn{2}{|c|}{$\begin{array}{l}\text { LSTAR- } \\
\text { LSTARCH }\end{array}$} & \multicolumn{2}{|c|}{$\begin{array}{c}\text { LSTAR- } \\
\text { LSTGARCH }\end{array}$} & \multicolumn{2}{|c|}{ LSTAR-ANLSTGARCH } \\
\hline & $T P$ & $E J P$ & $T P$ & $E J P$ & $T P$ & $E J P$ & $T P$ & $E J P$ & $T P$ & $E J P$ \\
\hline 50 & - & - & - & - & - & - & - & - & - & - \\
\hline 100 & - & - & - & - & - & - & - & - & - & - \\
\hline 200 & - & - & - & - & - & - & - & - & - & - \\
\hline 500 & - & - & - & - & - & - & - & - & - & - \\
\hline 1000 & - & - & - & - & - & - & - & - & - & - \\
\hline
\end{tabular}

Note: Tables 4-6 give the results of specifying ESTAR for LSTAR in the DGP in (12). At $\phi_{20}=0$, the simulator could not specify LSTAR and it reported matrix inversion problems. Also, TP performed better than EJP in selecting LSTAR from ESTAR DGP 


\section{SPECIFYING ASYMMETRIC STAR MODELS}

Table 5. Selection Frequencies of models at different $\phi_{20}$ with fixed $\theta=5$

\begin{tabular}{|c|c|c|c|c|c|c|c|c|c|c|}
\hline \multirow{3}{*}{$N$} & \multicolumn{9}{|c|}{$\phi_{20}=0, \theta=5$} & \\
\hline & \multicolumn{2}{|c|}{$\begin{array}{c}\text { LSTAR- } \\
\text { ARCH }\end{array}$} & \multicolumn{2}{|c|}{$\begin{array}{l}\text { LSTAR- } \\
\text { GARCH }\end{array}$} & \multicolumn{2}{|c|}{$\begin{array}{l}\text { LSTAR- } \\
\text { LSTARCH }\end{array}$} & \multicolumn{2}{|c|}{$\begin{array}{c}\text { LSTAR- } \\
\text { LSTGARCH }\end{array}$} & \multicolumn{2}{|c|}{ LSTAR-ANLSTGARCH } \\
\hline & $T P$ & EJP & $T P$ & EJP & $T P$ & EJP & $T P$ & EJP & $T P$ & EJP \\
\hline 50 & - & - & - & - & - & - & - & - & - & - \\
\hline 100 & - & - & - & - & - & - & - & - & - & - \\
\hline 200 & - & - & - & - & - & - & - & - & - & - \\
\hline 500 & - & - & 0.750 & 0.569 & - & - & 0.755 & 0.579 & 0.769 & 0.604 \\
\hline 1000 & - & - & 0.784 & 0.638 & - & - & 0.786 & 0.641 & 0.790 & 0.629 \\
\hline
\end{tabular}

\begin{tabular}{|c|c|c|c|c|c|c|c|c|c|c|}
\hline \multicolumn{11}{|c|}{$\phi_{20}=0.2, \theta=5$} \\
\hline \multirow[t]{2}{*}{$N$} & \multicolumn{2}{|c|}{$\begin{array}{c}\text { LSTAR- } \\
A R C H\end{array}$} & \multicolumn{2}{|c|}{$\begin{array}{l}\text { LSTAR- } \\
\text { GARCH }\end{array}$} & \multicolumn{2}{|c|}{$\begin{array}{l}\text { LSTAR- } \\
\text { LSTARCH }\end{array}$} & \multicolumn{2}{|c|}{$\begin{array}{c}\text { LSTAR- } \\
\text { LSTGARCH }\end{array}$} & \multicolumn{2}{|c|}{ LSTAR-ANLSTGARCH } \\
\hline & $T P$ & $E J P$ & $T P$ & $E J P$ & $T P$ & $E J P$ & $T P$ & $E J P$ & $T P$ & $E J P$ \\
\hline 50 & - & - & - & - & - & - & - & - & - & - \\
\hline 100 & - & - & - & - & - & - & - & - & - & - \\
\hline 200 & - & - & - & - & - & - & - & - & - & - \\
\hline 500 & - & - & 0.614 & 0.470 & - & - & 0.612 & 0.482 & 0.659 & 0.527 \\
\hline 1000 & - & - & 0.673 & 0.554 & - & - & 0.657 & 0.546 & 0.718 & 0.563 \\
\hline
\end{tabular}

\begin{tabular}{ccccccccccc}
\multicolumn{10}{c}{$\phi_{20}=0.5, \theta=5$} \\
\hline \multirow{2}{*}{$N$} & LSTAR- & \multicolumn{10}{c}{ LSTAR- } & \multicolumn{2}{c}{ LSTAR- } & \multicolumn{2}{c}{ LSTAR- } & \multicolumn{2}{c}{ LSTAR-ANLSTGARCH } \\
& \multicolumn{1}{c}{ ARCH } & \multicolumn{2}{c}{ GARCH } & \multicolumn{2}{c}{ LSTARCH } & \multicolumn{2}{c}{ LSTGARCH } & \multicolumn{2}{c}{ TSTR } \\
& TP & EJP & TP & EJP & TP & EJP & TP & EJP & TP & EJP \\
\hline 50 & - & - & - & - & - & - & - & - & - & - \\
100 & - & - & - & - & - & - & - & - & - & - \\
200 & - & - & - & - & - & - & - & - & - & - \\
500 & - & - & - & - & - & - & - & - & - & - \\
1000 & - & - & - & - & - & - & - & - & - & - \\
\hline
\end{tabular}

Note: The results obtained here are similar to that of Table 4. 


\section{YAYA \& SHITTU}

Table 6. Selection Frequencies of models at different $\phi_{20}$ with fixed $\theta=10$

\begin{tabular}{|c|c|c|c|c|c|c|c|c|c|c|}
\hline \multicolumn{11}{|c|}{$\phi_{20}=0, \theta=10$} \\
\hline \multirow[t]{2}{*}{$N$} & \multicolumn{2}{|c|}{$\begin{array}{l}\text { LSTAR- } \\
\text { ARCH }\end{array}$} & \multicolumn{2}{|c|}{$\begin{array}{l}\text { LSTAR- } \\
\text { GARCH }\end{array}$} & \multicolumn{2}{|c|}{$\begin{array}{c}\text { LSTAR- } \\
\text { LSTARCH }\end{array}$} & \multicolumn{2}{|c|}{$\begin{array}{c}\text { LSTAR- } \\
\text { LSTGARCH }\end{array}$} & \multicolumn{2}{|c|}{ LSTAR-ANLSTGARCH } \\
\hline & $T P$ & $E J P$ & $T P$ & $E J P$ & $T P$ & $E J P$ & $T P$ & $E J P$ & $T P$ & $E J P$ \\
\hline 50 & - & - & - & - & - & - & - & - & - & - \\
\hline 100 & - & - & - & - & - & - & - & - & - & - \\
\hline 200 & - & - & - & - & - & - & - & - & - & - \\
\hline 500 & - & - & 0.750 & 0.569 & - & - & 0.760 & 0.578 & 0.768 & 0.609 \\
\hline 1000 & - & - & 0.784 & 0.638 & - & - & 0.789 & 0.644 & 0.788 & 0.625 \\
\hline
\end{tabular}

\begin{tabular}{|c|c|c|c|c|c|c|c|c|c|c|}
\hline \multicolumn{11}{|c|}{$\phi_{20}=0.2, \theta=10$} \\
\hline \multirow[t]{2}{*}{$N$} & \multicolumn{2}{|c|}{$\begin{array}{c}\text { LSTAR- } \\
\text { ARCH }\end{array}$} & \multicolumn{2}{|c|}{$\begin{array}{l}\text { LSTAR- } \\
\text { GARCH }\end{array}$} & \multicolumn{2}{|c|}{$\begin{array}{c}\text { LSTAR- } \\
\text { LSTARCH }\end{array}$} & \multicolumn{2}{|c|}{$\begin{array}{c}\text { LSTAR- } \\
\text { LSTGARCH }\end{array}$} & \multicolumn{2}{|c|}{ LSTAR-ANLSTGARCH } \\
\hline & $T P$ & $E J P$ & $T P$ & EJP & $T P$ & $E J P$ & $T P$ & $E J P$ & $T P$ & $E J P$ \\
\hline 50 & - & - & - & - & - & - & - & - & - & - \\
\hline 100 & - & - & - & - & - & - & - & - & - & - \\
\hline 200 & - & - & - & - & - & - & - & - & - & - \\
\hline 500 & - & - & 0.614 & 0.470 & - & - & 0.612 & 0.482 & 0.656 & 0.527 \\
\hline 1000 & - & - & 0.673 & 0.554 & - & - & 0.655 & 0527 & 0.714 & 0.552 \\
\hline
\end{tabular}

\begin{tabular}{|c|c|c|c|c|c|c|c|c|c|c|}
\hline \multicolumn{11}{|c|}{$\phi_{20}=0.5, \theta=10$} \\
\hline \multirow[t]{2}{*}{$N$} & \multicolumn{2}{|c|}{$\begin{array}{l}\text { LSTAR- } \\
\text { ARCH }\end{array}$} & \multicolumn{2}{|c|}{$\begin{array}{l}\text { LSTAR- } \\
\text { GARCH }\end{array}$} & \multicolumn{2}{|c|}{$\begin{array}{c}\text { LSTAR- } \\
\text { LSTARCH }\end{array}$} & \multicolumn{2}{|c|}{$\begin{array}{c}\text { LSTAR- } \\
\text { LSTGARCH }\end{array}$} & \multicolumn{2}{|c|}{ LSTAR-ANLSTGARCH } \\
\hline & $T P$ & $E J P$ & $T P$ & $E J P$ & $T P$ & EJP & $T P$ & $E J P$ & $T P$ & $E J P$ \\
\hline 50 & - & - & - & - & - & - & - & - & - & - \\
\hline 100 & - & - & - & - & - & - & - & - & - & - \\
\hline 200 & - & - & - & - & - & - & - & - & - & - \\
\hline 500 & - & - & - & - & - & - & - & - & - & - \\
\hline 1000 & - & - & - & - & - & - & - & - & - & - \\
\hline
\end{tabular}

Note: The results obtained here seem to improve insignificantly over that of Table 5.

\section{Conclusion}

This study considered the specification of asymmetric Smooth Transition Autoregressive (STAR) models with linear and nonlinear GARCH innovations. The GARCH error specifications are those proposed already in the literature. 


\section{SPECIFYING ASYMMETRIC STAR MODELS}

Specifications of the Logistic STAR-GARCH (LSTAR-GARCH) variants were carried out using the usual STAR specification procedures. The empirical results showed strong support for modelling STAR models with different GARCH error specifications. The results further showed that STAR model in STAR-GARCH model cannot be misrepresented in the real sense.

\section{References}

Acemoglu, D. \& Scott, A. (1994). Asymmetries in the cyclical behaviour of UK labour markets. Economic Journal, 104: 1303-1323.

Anderson, H. M., Nam, K. \& Vahid, F. 1999. Asymmetric nonlinear smooth transition GARCH models. Rothman, P., (editor) Nonlinear time series analysis of economic and financial data (pp. 191-207). Boston, MA: Kluwer.

Baum, C. F., Caglayan, M. \& Barkoulas, J. T. (1998). Nonlinear adjustment to purchasing power parity in the post-Bretton woods era. Working paper No. 404, Department of Economics, Boston College.

Black, F. (1976). The pricing of commodity contracts, Journal of Financial Economics, 3: 167-179.

Bollerslev, T. (1986). Generalized autoregressive conditional heteroscedasticity. Journal of Econometrics, 31: 307-27.

Chan, K. \& McAleer, M. (2002). Maximum Likelihood Estimation of STAR and STAR-GARCH Models: Theory and Monte Carlo Evidence. Journal of applied Econometrics, 17: 509-534.

Ding, Z., Granger, C. W. J. \& Engle, R. F. (1993). A long memory property of stock market returns and a new model. Journal of Empirical Finance, 1: 83106.

Engle R. (1982). Autoregressive conditional heteroscedasticity, with estimates of the variance of United Kingdom inflation. Econometrica 50: 9871007.

Engle, R. F. \& Bollerslev, T. (1986). Modelling the persistence of conditional variances. Econometric Reviews, 5(1): 1-50.

Escribano, Á. \& Jordá, O. (2001). Testing nonlinearity: Decision Rules for Selecting between Logistic and Exponential STAR models. Spanish Economic review, 3: 193-209. 
Escribano, A., Franses, P. H. \& van Dijk, D. (1998). Nonlinearities and Outliers: Robust Specification of STAR Models. Econometric Institute Research Report 9832/A.

Franses, P. H. \& van Dijk, D. 2003. Nonlinear Time Series Models in Empirical Finance. Cambridge: Cambridge University Press.

Glosten, L. W., Jaganathan, R. \& Runkle, D. E. (1993). On the relation between the expected value and the volatility of the nominal excess return on stocks. Journal of Finance, 48: 1779-801.

González-Rivera, G. (1998). Smooth Transition GARCH models. Studies in nonlinear Dynamics and Econometrics, 3: 61-78.

Granger, C. W. J. \& Teräsvirta, T. (1993). Modelling Nonlinear Economic

Relationships. Oxford: Oxford University Press. Chinese edition 2006: Shanghai University of Finance and Economics Press.

Hagerud, G. E. (1996). A smooth transition Arch model for asset returns. Working Paper Series in Economics and Finance 162, Department of Finance, Stockholm School of Economics.

Hagerud, G. E. (1997). Specification tests for Asymmetric ARCH. Working paper. Stockhold School of Economics.

Higgins, M. L. \& Bera, A. K. (1992). A class of nonlinear ARCH models. International Economic Review, 33: 137-158.

Liew, V. K. S., Ahmad, Z. B. \& Sie-Hoe, L. 2002. Forecasting Performance of Logistic Smooth Transition Autoregressive Exchange Rate model: The Original and Re-parameterised versions. MPRA Paper 511: pp 1-20.

Lopes, H. F. \& Salazar, E. (2006). Time Series Mean Level and Stochastic Volatility Modelling by Smooth Transition Autoregressions: A Bayesian Approach. Advances in Econometrics, 20: 225-238.

Lundbergh, S. \& Teräsvirta, T. (1999). Modelling Economic high Frequency Time series with STAR-STGARCH models. SSE/EFI Working Paper Series in Economics and Finance, No. 291.

Luukkonen, R., Saikkonen, P. \& Teräsvirta, T. (1988). Testing linearity against smooth transition autoregressive models. Biometrica 75: 491-499.

Mourelle, E., Cuestas, J. C. \& Gil-Alana, L. A. (2011). Is there an Asymmetric Behaviour in African Inflation? A Non-linear Approach. South African Journal of Economics, 79: 68-88. 


\section{SPECIFYING ASYMMETRIC STAR MODELS}

Nam, K., Pyun, C. S. \& Arize, A. C. (2002). Asymmetric mean reversion and contrarian profits: ANST-GARCH approach. Journal of Empirical Finance, 9: $563-588$.

Nelson, D. B. (1991). Conditional heteroscedasticity in asset returns: A new approach. Econometrica, 59: 347-370.

Öcal, N. (2000). Nonlinear Models for U.K. Macroeconomic Time Series. Studies in Nonlinear Dynamics and Econometrics, 43: 123-135.

Pavlidis, E. G., Paya, I. \& Peel, D. A. (2010). Specifying Smooth Transition

Regression Models in the Presence of Conditional Heteroscedasticity of Unknown form. Studies in Nonlinear Dynamics and Econometrics, 143: 1-37.

Skalin, J. \& Terasvirta, T. (1996). Another look at Swedish business cycles. Working paper series in Economic and Finance. No. 130, Stockholm School of Economics.

Skalin, J. \& Teräsvirta, T. (1998). Modelling Asymmetries in Unemployment rates, Mimeo, Stockholm School of Economics.

Shittu, O. I. \& Yaya, O. S. (2011). On Fractionally Integrated Logistic Smooth Transitions in Time Series. Central Bank of Nigeria Journal of Applied Statistics, 2(1): 1-13.

Teräsvirta, T. (1994). Specification, Estimation and Evaluation of Smooth Transition Autoregressive Models. Journal of the American Statistical Association, 89: 208-218.

Teräsvirta, T. \& Anderson, H. M. (1992). Characterizing nonlinearities in Business cycles using Smooth Transition Autoregressive models. Journal of Applied Econometrics, 7: S119- S136.

Teräsvirta, T., Lin, C-F. J. \& Granger, C. W. J. (1993). Power of the neural network linearity test. Journal of Time Series Analysis, 14: 209-220.

Yaya, O. S. (2013). On the variants of Nonlinear models. PhD Thesis. Department of Statistics, University of Ibadan.

Yaya, O. S. \& Shittu, O. I. (2011). On Misspecification of Exponential Transition Models with GARCH Error Terms: The Monte Carlo Evidence. Proceedings of the $58^{\text {th }}$ World Statistical Congress of the International Statistical Institute, Dublin. Section CPS001: 5907-5912. 